\title{
Detecção de padrões da forma urbana: Quadro geral e um Caso
}

\author{
Urban form pattern detection: Background and one Case
}

Romulo Krafta[a] (ㄱ), Edson Luiz Bortoluzzi da Silva[b] (1)

[a] Universidade Federal do Rio Grande do Sul (UFRGS), Porto Alegre, RS, Brasil

[b] Universidade Federal de Santa Maria (UFSM), Santa Maria, RS, Brasil

Como citar: Krafta, R., \& Silva, E. L. B. (2020). Detecção de padrões da forma urbana: Quadro Geral e um Caso. urbe. Revista Brasileira de Gestão Urbana, v.12, e20190209. https://doi.org/10.1590/2175-3369.012.e20190209.

\section{Resumo}

0 artigo discute diferentes formas de identificar e medir padrões da forma urbana, considerando distintas abordagens - figurativa, geométrica e configuracional - e diferenciando descrições de estado (estáticas) e representações da sua evolução (dinâmicas). Uma captura de padrão de mudança é apresentada em maior detalhe, na qual recursos analíticos de física estatística são utilizados. Para isso, um estudo de caso - a cidade de Santa Maria/RS - explora as relações entre processos de longo prazo de densificação e de expansão urbanas, em que são produzidas evidências de haver entre ambos uma relação caracterizada como de criticalidade auto-organizada. 0 estudo de caso, bem como a maioria dos demais enunciados teóricos e métodos analíticos, constitui referências da produção científica do Grupo de Pesquisa Sistemas Configuracionais Urbanos do Programa de Pós-Graduação em Planejamento Urbano e Regional da Universidade Federal do Rio Grande do Sul.

Palavras-chave: Morfologia Urbana. Análise Espacial. Dinâmica Espacial Urbana.

\section{Abstract}

This article reports discussion of different ways of describing and assessing urban form patterns, considering various approaches as figurative, geometric, and configurational, distinguishing between static and evolutionary descriptions. It also presents a case of urban form change pattern in more detail, in which methods originally used in statistical physics are applied. The case-study, the city of Santa Maria Brazil, explores the relationship between long term evolution of densification and expansion. The evidence suggests that such relationship is consistent with processes already described as self-organized criticality. Thus, as well as the majority of theoretical statements and analytical methods constitute references of scientific output of the Research Group "Sistemas Configuracionais Urbanos", from the Graduate Programme of Urban and Regional Planning of the Federal University of Rio Grande do Sul.

Keywords: Urban Morphology, Spatial Analysis, Urban Spatial Dynamics.

RK é PhD em Ciência Urbana, e-mail: krafta@ufrgs.br

ELBS é doutor em Planejamento Urbano e Regional, e-mail: edsonlbsilva@gmail.com 


\section{Introdução}

O objetivo fundamental do estudo da forma urbana é buscar, identificar e explicar a ocorrência de padrões. Por padrão se entende algum tipo de regularidade, homogeneidade ou distribuição, normalmente associado às noções de ordem e de estrutura urbanas. Ordem é uma palavra muito cara ao urbanismo, representando a essência mesmo da disciplina; produzir ordem equivale a construir um arcabouço físico capaz de gerar funcionalidade, beleza, eficiência e equidade - em uma palavra, urbanidade. Entretanto, ordem é um conceito elusivo em urbanismo frequentemente associado à combinação de racionalidade e emoção, ambas derivadas da vontade de um autor. Ações (proposições) autorais inevitavelmente se chocam com outra ordem, a qual, de certa forma, é oposta à primeira por ser emergente, quer dizer, resultado da combinação de muitas ações autorais simultâneas e incidentes sobre o mesmo território. Ordem morfológica, por consequência, difere muito da ordem arquitetônica justamente por ser uma superposição desordenada, por assim dizer, de ordens impostas por autores individuais. Ordem urbana, nesse sentido, resulta da confrontação e submissão de ordens particulares a um "resultado" inesperado e imprevisível.

Este tem sido o desafio da morfologia urbana desde Muratori (Gauthier, 2004), pelo menos: demonstrar que essa ordem emergente existe, quer dizer, que o resultado da superposição no espaço de milhões de ações individuais, todas elas feitas segundo vontades e conveniências particulares e autônomas ao longo do tempo, não é aleatório.

Estrutura é outro conceito importante no urbanismo e igualmente desafiador, entendido, em uma primeira e mais elementar instância, como um conjunto de componentes mais importantes de uma composição, evoluindo para um entendimento mais elaborado e envolvendo permanência - elementos que ancoram uma composição que pode mudar, desde que sempre em torno de componentes que lhe dão estabilidade. Estrutura, finalmente, ganha em abstração ao ser pensada como um processo ou sistema de relações entre componentes, permitindo diferentes configurações a partir de um mesmo código genético, por assim dizer.

Descrever ordem e estrutura da forma urbana parece, como efetivamente ocorreu, um grande desafio por dois motivos: primeiro por contrariar o senso comum, que sugere ser a forma urbana um subproduto de processos socioeconômicos e políticos "superiores", ou seja, subjacentes e determinantes; segundo por tentar abarcar um fenômeno suficientemente grandioso - a maior obra coletiva da humanidade, imensamente diversificado e incrivelmente mutável. Este estudo se propõe a, em um primeiro momento, destacar os principais artifícios teórico-metodológicos utilizados na detecção de padrões da forma urbana e, em um segundo, explorar em mais detalhe um deles, de utilização mais recente. 0 material aqui apresentado resume, em grande parte, o trabalho de investigação levado a cabo no Grupo de Pesquisa Sistemas Configuracionais Urbanos do Programa de Pós-Graduação em Planejamento Urbano e Regional da Universidade Federal do Rio Grande do Sul.

\section{Um quadro geral de meios - Descrição de Estado}

A Tabela 1 procura cobrir os principais meios de detecção de padrões da forma urbana. Está organizada segundo uma vaga ordem cronológica, ao mesmo tempo que diferencia os meios de descrição estáticos (descrição de estado da forma urbana) e dinâmicos (descrição da mudança de estado da forma urbana). Não pretende ser exaustivo, isto é, registrar cada um e todos os meios já elaborados para a detecção de padrões, mas se referir aos mecanismos fundamentais, utilizados segundo possíveis diferentes contextos e combinações, com base na experiência do Grupo de Pesquisa Sistemas Configuracionais Urbanos. 
Tabela 1 - Quadro geral de análise e detecção de padrões morfológicos

\begin{tabular}{|c|c|c|c|c|}
\hline$t$ & Abordagem & Núcleo teórico (padrão) & Modelo descritivo & Verificação \\
\hline \multirow[t]{7}{*}{$t_{i}$} & Tipológica & Similaridade & Área temática & Visual (diagramas) \\
\hline & Geométrica & Regularidade & Retículas & Dimensional \\
\hline & & Fractalidade & Potências $1><2,2><3$ & Assinatura \\
\hline & & & Acessibilidade & \\
\hline & & & Centralidade & \\
\hline & Espacial & Hierarquia & Informação & Rankings \\
\hline & & & $\begin{array}{c}\text { Outros } \\
\text { (grafo direcionado) }\end{array}$ & \\
\hline \multirow[t]{13}{*}{$t_{i \gg n}$} & Tipológica & Evolução tipológica & Mudanças no tipo & Visual (diagramas) \\
\hline & & Morfogenética & Áreas homogêneas & Visual (mapas) \\
\hline & Geométrica & Variação topológica & Retículas & Dimensional \\
\hline & Espacial & Desenvolvimento desigual & Potencial-centralidade & $\begin{array}{c}\text { Correlação } \\
\text { Estatística espacial }\end{array}$ \\
\hline & & Indução por & Autômato celular & Estatística espacial \\
\hline & & vizinhança & Cadeia de Markov & Entropia/complexidade \\
\hline & & Feedback positivo & Equação logística & Regressão \\
\hline & & Criticalidade auto- & $\begin{array}{l}\text { Distância crítica } \\
\text { Densidade }\end{array}$ & Ponto crítico \\
\hline & & organizada & $x$ & Leis de potência \\
\hline & & & Expansão & \\
\hline & & & Forma construída & \\
\hline & & & $\begin{array}{c}\text { X } \\
\text { Centralidade }\end{array}$ & \\
\hline & & Metabolismo & Alometria & Projeções comparadas \\
\hline
\end{tabular}

Nota: "t" significa "tempo", "ti" significa um instante qualquer, "ti>>n" significa um intervalo de tempo.

A primeira coluna distingue os meios destinados a revelar padrões de estado, isto é, padrões exibidos em determinado momento $\left(\mathrm{t}_{\mathrm{i}}\right)$, daqueles empregados para descrever a evolução da forma urbana, quer dizer, padrões dinâmicos $\left(\mathrm{t}_{\mathrm{i}>>n}\right)$, de mudança. Essa distinção se dá em razão de que nem todos os processos de detecção de padrões de estado são aplicáveis a padrões evolutivos, sendo estes mais difíceis de serem caracterizados.

A segunda coluna tenta capturar os princípios fundamentais em que se apoiam os principais procedimentos analíticos disponíveis; aqui basicamente deverão aparecer os diferentes tipos de padrão morfológico/espacial perseguidos. São chamados de núcleos teóricos porque efetivamente se aproximam de enunciados descritivos e eventualmente explanatórios do fenômeno em questão. A terceira coluna procura identificar os modelos respectivos, ou seja, os meios analíticos destinados a produzir evidências que possam corroborar aqueles enunciados teóricos. Finalmente, a quarta coluna busca destacar a natureza mesma dessas evidências, as quais, como será visto, podem ir de simples verificação visual até elaborados métodos estatísticos.

\section{Abordagem tipológica}

Classificação tipológica é o processo indutivo mais utilizado para reduzir complexidade, agrupando objetos segundo determinados e previamente escolhidos atributos. Mediante esse processo, não apenas a enorme variedade de indivíduos únicos e originais fica reduzida a uma quantidade manejável de tipos, mas também associações entre tipos acaba sendo encontrada. Classificação tipológica é mais comumente encontrada em aplicações para a forma construída, quando então coleções de vários milhares de edificações individuais podem ser agrupadas em um número reduzido de tipos; não obstante, procedimento similar pode ser aplicado, talvez com menor eficácia, ao universo do espaço público e mesmo ao espaço aberto privado. Isso se deve à relativa grande quantidade de atributos relevantes da 
forma construída (dimensões e proporções, tipos de plantas, simetrias, estilos e outras características de safra etc.) utilizáveis para uma classificação, comparada aos poucos atributos do espaço público ou da partição fundiária (geratriz e dimensões para o espaço público, dimensões, proporções e distribuição para o espaço privado).

Identificação de tipos, entretanto, não é suficiente para revelar padrões morfológicos por causa da disposição relativa destes, primeiro, nos âmbitos próprios da forma construída e espaços públicos e privados - formação de uma trama de caminhos, blocos de lotes e agregados de edificações - e, segundo, na formação do tecido urbano - relações entre edificações, lotes e espaços públicos, a celebrada relação tipo-morfológica de Aymonino (1975). Do exame combinado de tipos e suas relações emerge, então, o modelo fundamental de análise da forma urbana nessa abordagem: a área temática. Pode-se definir área temática como sendo um fragmento de cidade onde é visível um padrão particular de disposição dos componentes da forma urbana, qual seja, um padrão de similaridade. A similaridade decorre da repetição de um ou mais tipos de edificação, espaço público e espaço privado, combinados segundo um conjunto de regras reconhecível.

Áreas temáticas, também denominadas zonas (Picinato,1947) ou regiões morfológicas (Conzen, 1988), podem não ser facilmente identificáveis, já que sua caracterização pode não incluir a totalidade das edificações, espaços públicos e lotes existentes. Com efeito, a verificação do tema depende da predominância de um certo número de tipos existentes em uma coleção de indivíduos que podem não ser, na sua totalidade, classificáveis como tais, e também depende do grau de rigidez aplicado à classificação. De qualquer forma, a noção de área temática conduz naturalmente à visão de uma cidade feita da sucessão de inúmeras delas, simplesmente justapostas umas às outras, ou eventualmente interconectadas por elementos diferenciados - monumentos (Rossi, 1998) ou estrutura primária (Krafta, 2014) -, configurando uma ordem morfológica. Aqui se tem, então, a emergência de uma ordem, dada como uma distribuição particular, não repetível como forma urbana concreta, apesar de reconhecível enquanto padrão genérico de sua organização. Sua verificação é visual, normalmente por meio de diagramas e mapas ilustrativos dos tipos, agregações e distribuições no território urbano.

\section{Abordagem geométrica}

Tradicionalmente, a abordagem geométrica é euclidiana, ou seja, identifica características dimensionais e relacionais da forma urbana e procura extrair daí padrões de regularidade. Essa regularidade seria baseada na ocorrência consistente de dimensões e de disposições relativas (frequência e angularidade de intercessões, sequências dimensionais etc.). Referências iniciais mais importantes são dadas por Martin (1972), em "The grid as generator", e também por March \& Steadman (1971), em que dimensões (área e volume) e disposições relativas (distribuição de unidades de volume edificado em diferentes distribuições territoriais - de central a periférica), seguindo o diagrama de Fresnel (Martin, 1972), demonstram a flexibilidade das retículas para gerar diferentes formas urbanas.

É interessante observar aqui o deslocamento desde uma visão figurativa de cidade (tipológica) até outra (geométrica) mais abstrata, em que edificações, ruas e lotes urbanos dão lugar a linhas, áreas e volumes (Steadman, 2001). Nessa situação de muito maior fluidez, o padrão reconhecível possível deixa de ser similaridade e passa a ser regularidade, dada por regras de partição do território segundo um variado número de retículas superpostas e combinadas, bem como suas possibilidades de variação. A verificação de padrão, aqui, é matemática, seja por meio de geometria, seja por meio de álgebra booleana (March, 2010).

Uma abordagem alternativa, mais recente, é a baseada em geometria fractal (Batty \& Longley, 1994), que considera que as dimensões clássicas da geometria euclidiana (linha - 1; área - 2; e volume - 3) seriam apenas casos particulares, e de certa forma ideais, de um contínuo dimensional; assim, entre as dimensões 1 e 2 , assim como entre as dimensões 2 e 3, haveria dimensões "quebradas" ou "incompletas", tais como linhas não retilíneas, polígonos não convexos, abertos, massas incompletas etc. Cidades são, 
claramente, objetos com geometria fractal, visto que suas linhas não são impecavelmente retilíneas, suas áreas não são regulares e sua volumetria é fragmentada; assim, são passíveis de ser descritas como tais. Áreas urbanas, dadas pelo perímetro externo do assentamento ou qualquer perímetro interno, de zonas urbanas, são não apenas figuras irregulares e fragmentadas, mas também similares (as partes e o todo compartilham a mesma dimensão fractal, não importando a escala). Se, na abordagem tradicional, o padrão geométrico é verificado pela regularidade dimensional, bem como pelas relações entre as diferentes retículas presentes no tecido urbano, o padrão fractal seria dado pela regularidade observada na dimensão fractal das diferentes formas urbanas observadas, quer dizer, o intervalo de variação da potência (varia entre 1 e 2 , e entre 2 e 3). A verificação de padrão se daria pela identificação de uma assinatura, ou seja, um intervalo estável de variação das medidas fractais de cidades.

\section{Abordagem espacial (ou configuracional)}

A abordagem espacial parte do princípio de que a cidade seria constituída de um conjunto imenso de células desigualmente distribuídas sobre o território, as quais estariam justapostas e superpostas umas às outras, cobrindo inteiramente o solo, e estariam conectadas umas às outras de maneira seletiva (cada célula tem um certo número de vizinhas - células justapostas ou superpostas - a si própria, mas não se conecta a todas indistintamente). Decorrente disso, toda e qualquer célula é alcançável desde qualquer outra, embora na grande maioria dos casos essa alcançabilidade seja realizada por meio de percursos envolvendo uma grande quantidade de células intermediárias.

Nessa visão, o território seria compartimentado consecutiva e crescentemente, conforme vias públicas (primeira instância), lotes (segunda), edificações (terceira) e pavimentos superpostos (quarta) acrescentados ao sistema, gerando uma distribuição desigual de células, uma espécie de topografia artificial, caracterizada por grande concentração de células em certas regiões e por menores concentrações, até situações de rarefação, em outras. Essa distribuição de células seletivamente interconectadas certamente cria um padrão que precisa ser adequadamente descrito. Essa descrição demanda, entretanto, maior elaboração, visto que características figurativas e dimensionais não são eficazes. Mesmo intuitivamente, é possível inferir que esse padrão, dado pela ligação possível (alcançabilidade) entre cada par de células, obtido por cadeias de células interligadas, é hierárquico.

Vários modelos de captura e representação de hierarquia espacial urbana foram criados e testados nos últimos anos, entre os quais os mais populares são:

- Modelo de acessibilidade, que utiliza como núcleo lógico o princípio de distância relativa (soma do inverso das distâncias de um ponto a todos os demais). Assim, para um sistema de n células, cada uma terá um escore obtido pela soma de distâncias desde si a todas as n-1 outras células do sistema. O modelo básico já caracterizado pode ser adaptado a diferentes modos de descrever células de um sistema, modos de medir distância e ainda pela inclusão de qualificadores, tais como função não linear de declínio da distância e função gravitacional associada a porte e/ou conteúdo das células (Hansen, 1959; Ingram, 1971; Hillier \& Hanson, 1985; Krafta, 2014).

- Modelo de centralidade, que utiliza como núcleo lógico o princípio de posição relativa, ou betweenness. Segundo Freeman (1977), haverá centralidade desse tipo sempre que a alcançabilidade de uma célula a outra qualquer envolva a participação de uma terceira que constitua o caminho mínimo do par em questão. Assim, ao considerar a totalidade de pares de células de um sistema e, para cada um, identificar quais outras células constituem o caminho mínimo respectivo, tem-se por soma simples a centralidade de cada célula por posição relativa; a mais central será a que mais vezes comparece na alcançabilidade. Tendo sido desenvolvido originalmente para descrever hierarquia em redes sociais, o modelo básico de centralidade também pode ser refinado, visando abranger outras particularidades do sistema urbano, tais como diferentes formas de representar células, medir distância e incluir função gravitacional destinada a ponderar porte das células (Krafta, 2014). Com isso, uma medida de 
centralidade urbana incluiria variáveis relativas à posição no espaço (conectividade, distância relativa) e carregamento (densidade edilícia).

- Modelo de informação, que se vale da noção de que cada componente de um sistema espacial detém uma certa quantidade de informação, a qual, se suprimida, provoca uma perda de desempenho do sistema. A hierarquia, assim, será revelada pela verificação de quanta perda o sistema sofre pela supressão de cada célula. Sua medição envolve a adoção de uma medida de desempenho, que será calculada primeiro para o sistema integral e depois, sucessivamente, para o sistema integral menos uma das células, a suprimida. A comparação dessas duas medições revela a hierarquia de cada célula.

A verificação da hierarquia espacial dos sistemas urbanos se dá quantitativamente por rankings de hierarquia, centralidade etc., que revelam a posição de cada célula segundo sua distância ou posição relativa. É relevante mencionar que, diferentemente das abordagens anteriores aqui referidas, a espacial está conceitualmente vinculada à noção de sistemas. Com efeito, nesse tipo de análise estão presentes os elementos fundamentais de um sistema: um certo (e grande) número de componentes, mantidos coesos por relações internas fortes o suficiente para fazer o conjunto depender de cada uma de suas partes. A adjacência entre duas células é justamente esse tipo de relação, simples na sua concepção, mas forte na sua consistência em manter todas as células alcançáveis, a ponto de tornar qualquer medida de hierarquia sensível em uma simples supressão de uma única célula, ou mesmo em uma simples modificação na adjacência entre duas células do conjunto.

Modelos de acessibilidade e centralidade podem dar origem a outros, derivados com base em grafos direcionados, isto é, que distinguem pontos de origem e de destino (Krafta, 1997) e dão margem a descrições específicas, tais como oportunidade espacial (ranking de privilégios de localizações residenciais em relação a pontos de oferta de serviços), convergência (ranking de privilégios de localizações comerciais em relação a uma distribuição de usuários) ou ainda polarização (centralidade resultante de um atrator específico).

A existência de um ou mais valores numéricos associados a cada célula do sistema, medindo a sua hierarquia, permite estender o alcance da análise, buscando relacionar a configuração espacial de cidades a outros aspectos de sua organização socioeconômica e vida cotidiana. Isso tem sido repetidamente levado a efeito mediante a correlação estatística entre hierarquia espacial e: a) distribuição do uso do solo; b) padrão de circulação viária e de pedestres; c) valor da terra urbana, entre outros, com relativo sucesso. Derivações dos modelos fundamentais também têm sido formuladas, tais como análise de oportunidade espacial, convergência e polarização. Basicamente são modelos que segmentam a verificação de hierarquia mediante o uso de grafos direcionados, isto é, identificando e pareando células de origem e de destino para propósitos específicos. Por esse meio, por exemplo, oportunidade espacial consegue medir privilégios locacionais residenciais em relação à oferta de determinados serviços; convergência provê uma medida de privilégio locacional de pontos de oferta de um certo serviço em relação a um conjunto de prováveis consumidores espacialmente identificados.

\section{Um quadro geral de meios - Análise Evolucionária}

Mudanças da forma urbana costumam ser lentas - de meses a anos ou, mais apropriadamente, de décadas a séculos, segundo Barthelemy (2019); não obstante, constituem fator determinante do estudo da forma urbana. Todas as abordagens aqui anteriormente descritas desenvolvem meios de capturar o processo evolucionário da forma urbana, à sua maneira. A seguir algumas delas serão apresentadas. 


\section{Abordagem figurativa}

\section{Evolução Tipológica}

A proposta de evolução tipológica vem de Muratori (Cataldi et al., 2002; Gauthier, 2004) e se refere à hipótese de continuidade do modo de produzir edificações de um lugar, mesmo submetido a mudanças. Evolução de um tipo iria se dar pela acumulação de pequenas mudanças ao longo de algum tempo, durante o qual é escasso o investimento em novas edificações. Nesse sentido, evolução tipológica seria não apenas a descrição de um processo passado, mas também a chave para sua continuidade no futuro (conceito de história operativa). A julgar por essa conceituação, evolução tipológica refere-se basicamente à forma construída, tendo pouco alcance como forma de representar a mudança urbana. Seus métodos descritivos são os mesmos - diagramas utilizados para descrever o estado da forma, dispostos de maneira a caracterizar uma sucessão.

\section{Morfogênese}

Morfogênese é o método desenvolvido por Conzen (1988) para descrever a evolução da forma urbana. Com base no conceito primário de "região morfológica" - um fragmento de tecido urbano que possui unidade com respeito à sua forma, que o distingue das áreas adjacentes -, esse método busca descrever meticulosamente a história de uma cidade desde o ponto de vista de sua morfologia, mapeando todas as suas regiões morfológicas. A identificação de uma região morfológica não é trivial, visto que seus diversos componentes têm ciclos de vida distintos; disso decorre que uma única região morfológica inicial possa evoluir, mediante troca de alguns componentes de vida menos longa, para a formação de várias regiões menores, a partir da recombinação de tipos originais e novos. Não por acaso, essa abordagem é conhecida como geografia histórica, dada a convergência de métodos de descrição eminentemente geográficos, porém aplicados segundo uma cronologia rigorosa.

Apesar do rigor descritivo com que a evolução de tipos edilícios e de áreas temáticas urbanas é tratada, teorias de evolução tipológica e morfogênese têm pouco poder explanatório, isto é, possuem poder limitado para revelar eventuais mecanismos implícitos nas mudanças descritas, assim como têm aplicabilidade limitada a certas cidades e a certos períodos históricos. Com efeito, autores dedicados a essas abordagens referem-se frequentemente à "crise" como sendo quebras evolutivas, pontos de ruptura para além dos quais as leis gerais de evolução tipológica não mais se aplicam. Dessa maneira, os diagramas e os mapas que descrevem situações originais (tipos historicamente determinados, formações morfológicas iniciais) e suas alterações ao longo do tempo (o aparecimento de tipos derivados e regiões morfológicas híbridas) parecem servir mais ao registro do passado do que como chaves para entender o presente/futuro.

\section{Abordagem Geométrica}

Mudanças da forma urbana vistas desde a sua dimensão geométrica envolvem processos de extensão, variação dimensional e justaposição/superposição de retículas, dos quais extensão e variação dimensional são processos que envolvem descrições relativamente simples; o primeiro se refere à reprodução de uma retícula (expansão da área urbana), envolvendo ou não o segundo, qual seja, variações de tamanho e forma das malhas e dos módulos. Maior interesse recai sobre processos de combinação de retículas (expansão da área urbana e disposição de edificações). Os mecanismos próprios de combinação de retículas (espaços abertos públicos e privados mais formas construídas) já haviam sido pioneiramente examinados por March \& Steadman (1971), que, ali aplicados para demonstrar possibilidades de configuração de planimetrias e volumetrias urbanas diferenciadas a partir de grelhas 
básicas, podem servir para descrever transições ocorridas na forma urbana, de formações compactas e forma "cheia" (predominância de formas construídas em espaços abertos) para formações mais recentes, que sugerem a inversão desse princípio.

Indicadores de geometria do ambiente construído urbano, como densidade edilícia, coeficientes de aproveitamento e taxa de ocupação de lotes ${ }^{1}$, têm sido utilizados há décadas para regrar a produção da forma urbana e para monitorar sua evolução (Pont \& Haupt, 2009; Porto Alegre, 1979; Krafta, 2014).

\section{Abordagem Espacial}

A abordagem espacial tem se revelado fértil com respeito à formulação de enunciados teóricos destinados a explanar a dinâmica urbana, e isso se deve, em parte, à proximidade que mantém com outras áreas das ciências naturais, particularmente a Física. A expressão "física social", já bastante usada para se referir a alguns desses enunciados (Ball, 2004; Batty, 2007; Barthelemy, 2019), atesta essa vizinhança e revela o interesse que a cidade despertou em pesquisadores de áreas que fundamentam seus estudos em sistemas complexos. Estes são caracterizados fundamentalmente por sua evolução - instabilidade, imprevisibilidade, dinâmica fora do equilíbrio -, ou seja, tratam de fenômenos em que a principal característica é a mudança. Cidades parecem ser exatamente isso, e a apropriação de meios analíticos dos sistemas complexos tem revelado diferentes aspectos dos padrões de evolução da forma urbana. A seguir alguns desses enunciados serão examinados - esse conjunto não esgota a pesquisa desse tópico e tende, inevitavelmente, a refletir a investigação levada a cabo no Grupo de Pesquisa Sistemas Configuracionais Urbanos.

\section{Desenvolvimento Desigual}

A característica fundamental dos sistemas complexos, de apresentar uma dinâmica fora do equilíbrio, deveria estar presente na evolução das cidades; intuitivamente, essa dinâmica poderia ser identificada como um desenvolvimento desigual ou desparelho. Apesar dos esforços dos planejadores urbanos para dirigir um desenvolvimento "controlado", as cidades teimam em fazer o oposto, isto é, manter simultaneamente áreas estagnadas e outras de desenvolvimento explosivo, promover desenvolvimento rápido em regiões inesperadas, e, muito antes de estas estarem efetivamente desenvolvidas, mudar para outras, concentrar edificação em alguns pontos e dissipá-la em outros etc. Uma tentativa de reproduzir esse tipo de dinâmica (Krafta, 1994) consiste em assumir a hierarquia espacial, dada em um momento t0 e capturada por meio de uma medida configuracional, como sendo expressão de um desequilíbrio estrutural que conduz à mudança. Nesse enunciado, a hipótese principal é que lugares urbanos menos centrais são mais propensos a apresentar mudanças mais radicais ${ }^{2}$. Lugares menos centrais, conforme a definição de centralidade (veja seção Modelo de Centralidade), seriam aqueles que apresentam simultaneamente posição relativa desfavorável e recurso edificado rarefeito (ou desvalorizado pela idade, obsolescência), ambas variáveis denotativas de baixo valor imobiliário.

O modelo "potencial-centralidade", desenvolvido para representar a dinâmica do desenvolvimento desigual, toma uma taxa de crescimento do recurso edilício exogenamente determinada e a distribui segundo probabilidades calculadas com base na centralidade diferencial das diferentes localizações urbanas. 0 padrão evolutivo obtido, consistente com dados empíricos de controle, mostra a seguinte dinâmica: uma área urbana, de mais baixa hierarquia, torna-se preferencial para desenvolvimento (ocupação intensiva de lotes vagos ou substituição de edificações de baixa densidade) que, cumulativamente, eleva sua hierarquia e, assim, diminui seu potencial para receber novos

\footnotetext{
1 Densidade edilícia é uma relação entre área construída e área urbana; coeficiente de aproveitamento de lote é a densidade edilícia específica de um lote; taxa de ocupação de um lote é a relação entre área do lote e parcela dele efetivamente ocupada com edificação.

2 Para mais informação sobre teoria do desenvolvimento desigual, ver Smith (1984).
} 
desenvolvimentos; quando essa elevação de centralidade provoca mudanças no ranking de centralidade, o desenvolvimento muda para outra área, e assim por diante, constituindo um padrão de desenvolvimento desigual e instável. A verificação pode ser feita mediante dois recursos: quantitativamente, pela comparação de séries históricas de rankings de centralidade e, estatisticamente, pela correlação entre simulações e distribuições reais de área edificada (Figura 1).
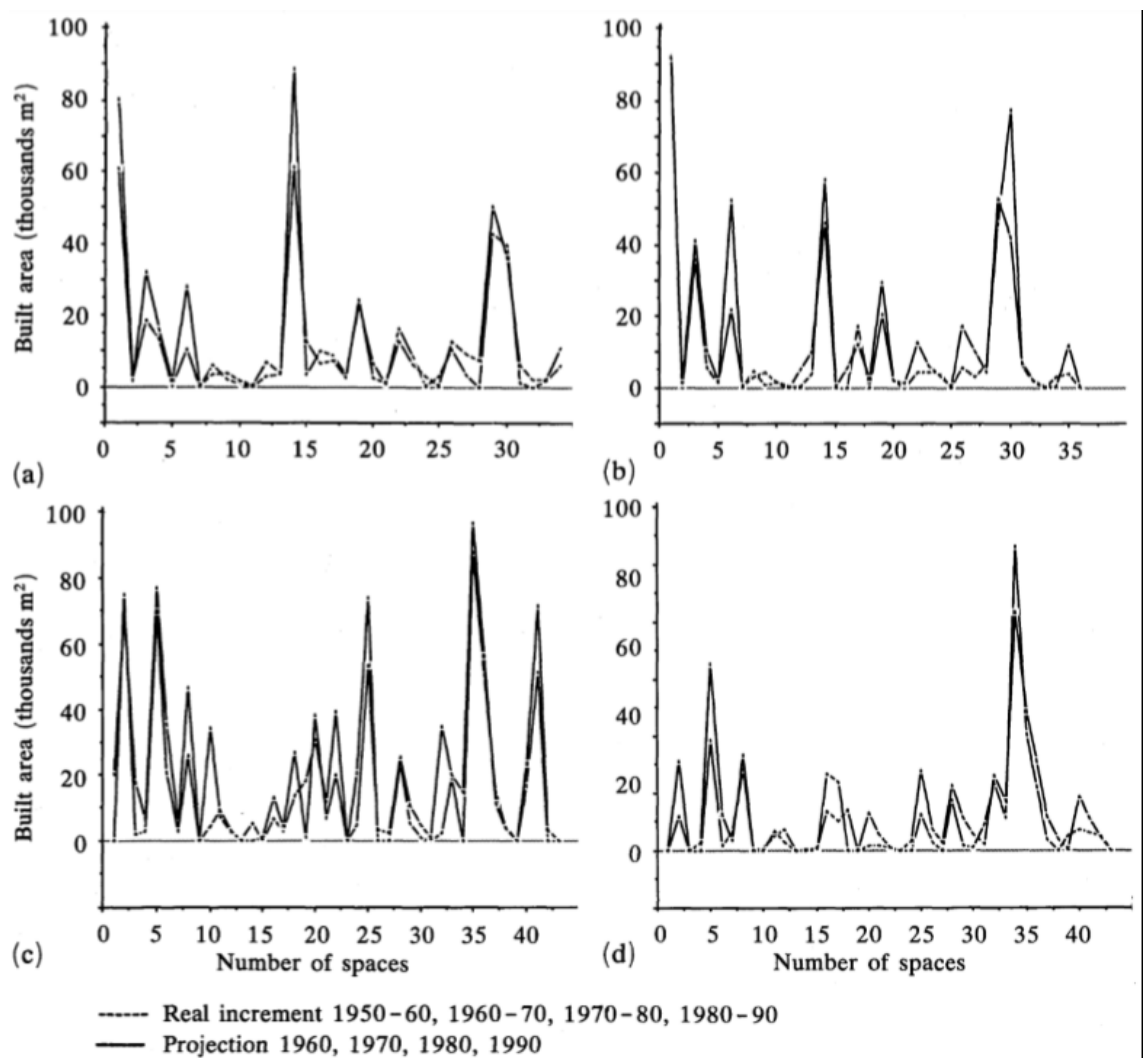

Figura 1 - Resultado da modelagem da evolução de uma área de Porto Alegre/RS usando modelo potencial-centralidade, mostrando a correlação entre modelo e dados empíricos. Fonte: Krafta,

1994, Modelling Intraurban Configurational Development, Environment \& Planning B.

\section{Indução por Vizinhança}

Outra característica básica dos sistemas complexos refere-se a nuvens densas de interação local, isto é, a um padrão resultante da relação de cada componente do sistema com alguns outros, mais próximos (definindo um tipo de interação trivial ou conhecida), porém levado a cabo simultaneamente por todos os componentes, quando então o padrão global é emergente. 0 enunciado urbano mais próximo disso é supor que cada célula, ou fragmento de tecido urbano, tenha seu estado e, mais ainda, suas probabilidades de mudança de estado influenciados fortemente pelas células vizinhas. Por essa via, pontos de desenvolvimento urbano mais intensos induziriam outros, próximos e menos intensamente desenvolvidos, a mudanças de estado. Visto localmente, o enunciado propõe uma dinâmica simples e direta: células mais intensamente desenvolvidas induziriam suas vizinhas menos desenvolvidas a mudar de estado; entretanto, ao considerar um grande conglomerado de células interligadas, cada uma exercendo e/ou recebendo influências de suas vizinhas, o padrão resultante é longe do trivial e esperado.

Pelo menos dois modelos simulatórios podem ser utilizados para representar a dinâmica espacial decorrente da indução por proximidade: modelos autômatos celulares e cadeias de Markov. Modelos Autômatos Celulares - AC são fundamentados em uma descrição espacial - uma matriz celular, em que cada célula, representando uma porção de espaço, possui um estado conhecido (urbano/não urbano, uso 
a, b, c, ... etc.), tem um número determinado de vizinhas conhecidas e uma dinâmica recursiva de atualização de estado. Essa dinâmica se caracteriza pela aplicação repetitiva de uma regra de determinação de estado, mediante a qual todas as células têm seu estado atualizado a cada iteração (White et al., 1997).

Aplicações típicas de modelos AC são para simulação de processos de expansão urbana e de competição intraurbana entre zonas de diferentes morfologias/usos. Legitimação de seus resultados envolve, primeiro, calibração, obtida mediante simulação de períodos evolutivos conhecidos (do passado ao presente), e, segundo, uso de estatística espacial para as diferentes etapas e opções de ajuste do modelo, mediante verificação de itens como extensão de perímetros, áreas e formas (shapes) das superfícies simuladas, comparadas com as reais, como na Figura 2 (Polidori \& Krafta, 2005).
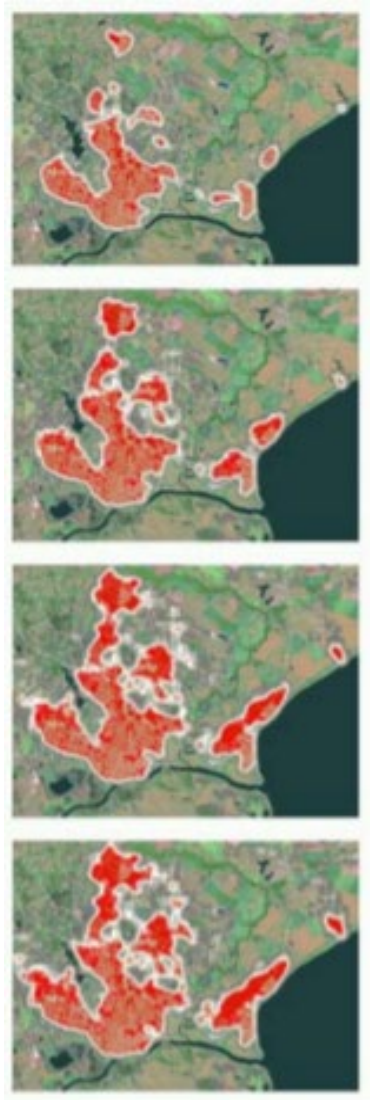
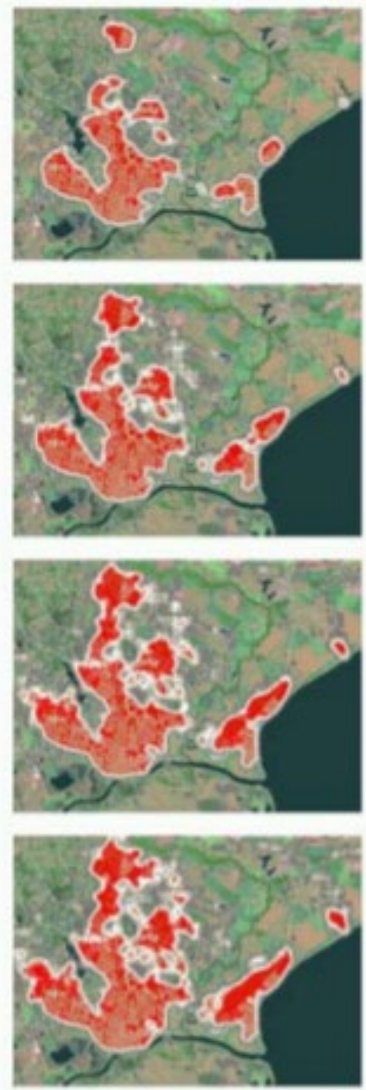
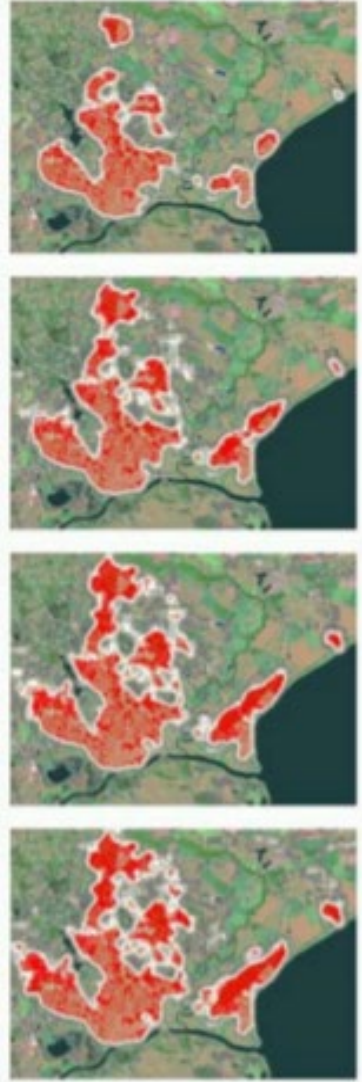
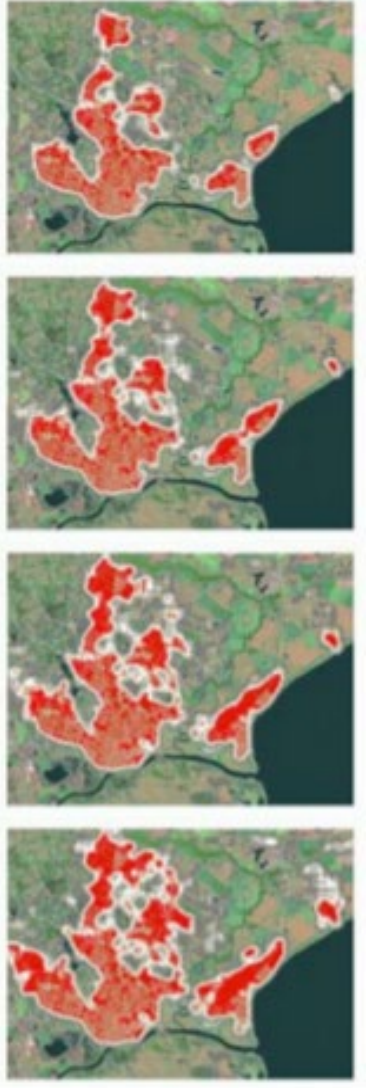

Figura 2 - Simulação do crescimento urbano de Pelotas/RS por autômato celular, para o período 2000-2045. Fonte: Polidori \& Krafta, 2005, Simulando Crescimento Urbano, Geofocus.

Cadeia de Markov é um modelo estocástico que descreve uma sequência de eventos possíveis, em que a probabilidade de ocorrência de um evento depende apenas do estado característico do evento que o precede. Também conhecido como o "princípio da falta de memória", por justamente dispensar o conhecimento prévio da evolução de um sistema. A cadeia de Markov tem se mostrado capaz de reproduzir processos evolutivos do tecido urbano, mais especificamente a evolução da forma construída, na qual diferentes tipos edilícios se sucedem em determinada região urbana, cada unidade fundiária sendo afetada por suas vizinhas (Constantinou \& Krafta, 2007). A verificação de padrão evolutivo aqui deve ser alcançada em dois estágios: um primeiro que ateste o comportamento do sistema como sendo compatível com os princípios do modelo; e um segundo que demonstre a convergência dos resultados das predições com o comportamento empírico do sistema (verificação da evolução passada). Para o primeiro, medidas de entropia e de complexidade são utilizadas; para o segundo, graus de correlação. Para ambos, o padrão emergente é um de propagação, ou seja, de extensão de limites de áreas caracterizadas por tipo de ocupação sobre outras (Figura 3). 

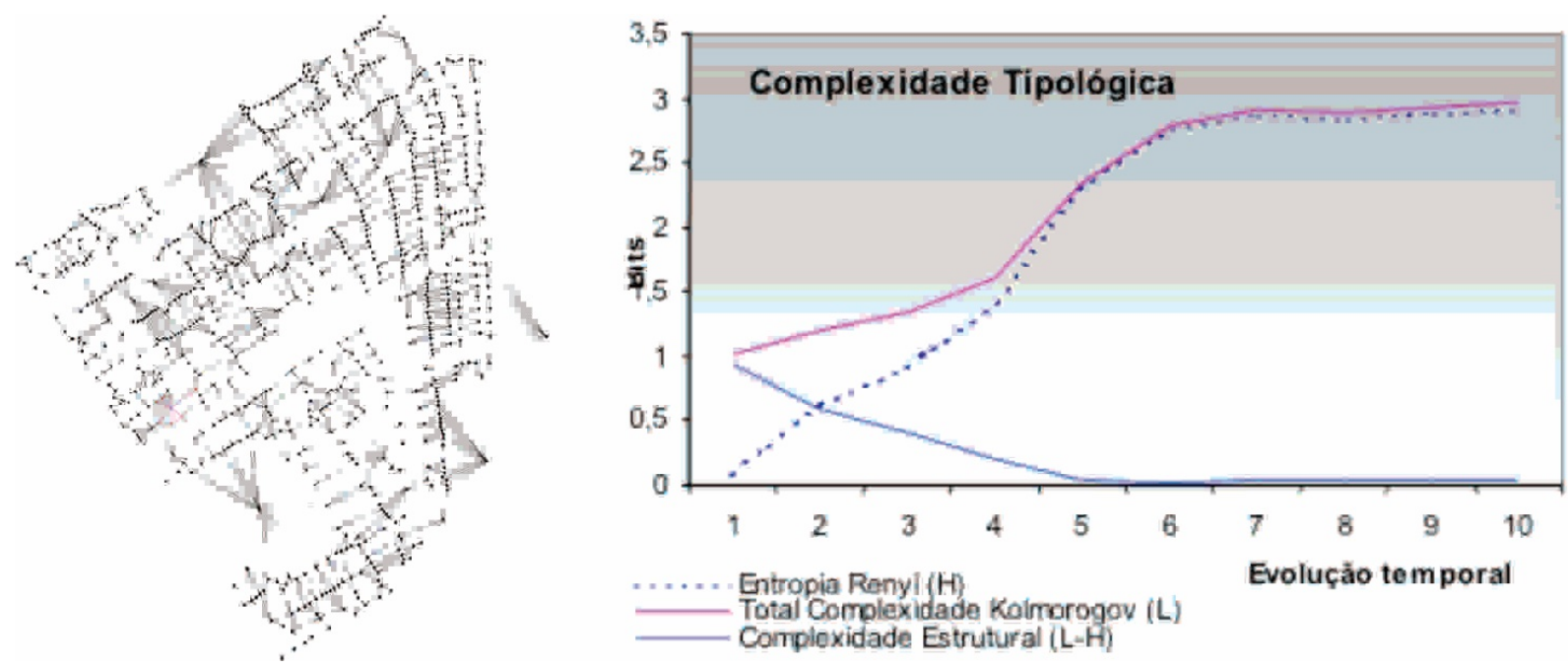

Figura 3 - Simulação de processo de substituição de tipos edilícios por cadeia de Markov; à esquerda, grafo de conectividades; à direita, medidas de entropia e complexidade do processo. Fonte: Constantinou \& Krafta, 2007, Built Form Change: Randomness and Emergence of Space-time Patterns, Proceedings of the International Seminar on Urban Form.

\section{Feedback Positivo}

Feedback positivo refere-se a processos evolutivos não lineares, fundamentados no princípio da "dependência do caminho", isto é, desenvolvimentos que podem iniciar em qualquer lugar, mas que, uma vez iniciados, desenvolvem uma dinâmica própria, utilizando a retroalimentação como força propulsora. Assumindo que cada acréscimo de forma construída, ocorrida em determinado ponto do tecido urbano, afeta a chance de outros ocorrerem nas adjacências, o desenvolvimento de uma região ocorreria em velocidades diferentes, lento nos primeiros momentos, acelerado em seguida e desacelerado mais adiante, até eventual saturação (que ocorreria antes de a região estar completamente ocupada ou renovada, segundo a teoria do desenvolvimento desigual, descrita na seção de mesmo nome). Simulação de processos de feedback positivo ou negativo pode ser instrumentada por modelos logísticos e verificada mediante ajuste de sua equação à série histórica de dados empíricos (Maraschin \& Krafta, 2013). 0 padrão emergente é um de crescimento a velocidade variável, como mostra a Figura 4.

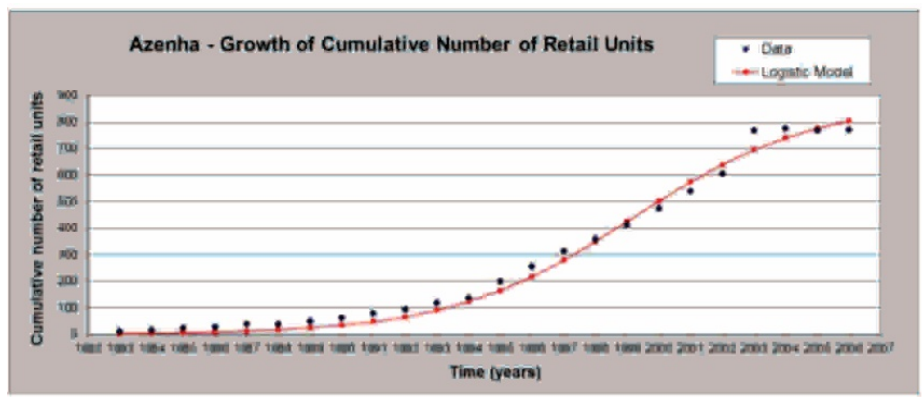

\begin{tabular}{|c|c|c|c|c|}
\hline \multirow{2}{*}{ Area } & \multicolumn{2}{|c|}{$\begin{array}{l}\text { Origin } \\
\text { growth }\end{array}$} & \multirow{2}{*}{\begin{tabular}{|l|} 
Growth Coefficient \\
$a$
\end{tabular}} & \multirow{2}{*}{\begin{tabular}{|l|} 
Growth Limit \\
N.
\end{tabular}} \\
\hline & $t_{0}$ & $\mathrm{~N}_{\mathrm{o}}$ & & \\
\hline City Centre & 1983 & 116 & 0.2357 & 4,714 \\
\hline Menino Deus & 1983 & 28 & 0.2958 & 1,479 \\
\hline Iguatemi & 1983 & 134 & 0.1942 & 4,855 \\
\hline Azenha & 1983 & 3 & 0.3507 & 877 \\
\hline
\end{tabular}

Figura 4 - Plotagem do ajuste da equação logística aos dados empíricos para um centro comercial de Porto Alegre/RS (esquerda) e coeficientes de crescimento dos vários centros comerciais testados (direita). Fonte: Maraschin \& Krafta, Growth Dynamics of Retail Locations, Cybergeo 650. 


\section{Alometria}

Estudos recentes (Bettencourt \& West, 2010) têm utilizado alometria para identificar padrões evolutivos nos sistemas urbanos. Alometria, também conhecida por biologia escalar, é o estudo das relações entre tamanho e forma, anatomia, fisiologia e comportamento de organismos em sua evolução. Aplicação de métodos de descrição alométrica a cidades, tomando população como medida básica de tamanho e a relacionando a diversos outros fatores do sistema urbano, como infraestrutura, serviços, equipamentos, renda, inovação e até produção de $\mathrm{CO} 2$, utilizando uma base de dados gigantesca, revelou a existência de relações não lineares entre eles. Alguns mostram comportamento superlinear, isto é, aumentam em proporção superior ao crescimento demográfico, enquanto outros são sublineares, mostrando ainda variações regulares com respeito a mudanças de escala.

Uma medida de variação morfológica foi tomada a partir de dados evolutivos da área urbana versus área construída da cidade de Santa Maria/RS, exibida na Figura 5, (Krafta \& Silva, 2019), mostrando uma relação superlinear (área construída crescendo mais do que área urbana) com valor próximo aos valores encontrados por Bettencourt \& West (2010).

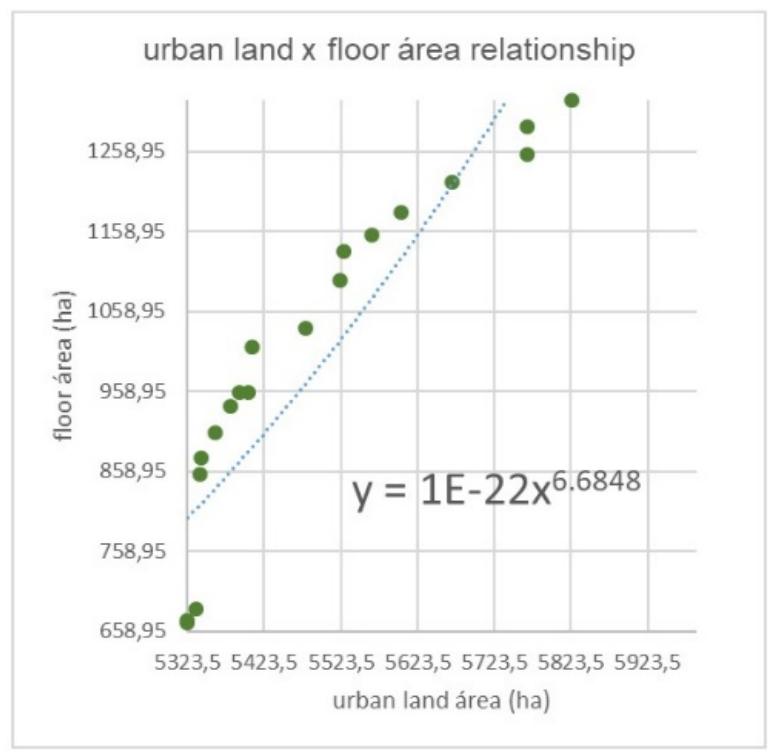

Figura 5 - Relação entre evolução da área urbanizada e área construída de Santa Maria/RS, mostrando desenvolvimento escalar superlinear dessa em relação. Fonte: Krafta \& Silva, 2019, Self-organized Criticality and Urban Form System Dynamics with reference to a Brazilian City, Area Development and Policy.

\section{Criticalidade Auto-Organizada - C.A.O.}

Um dos padrões de evolução mais elusivos dos sistemas complexos é o de criticalidade. Seu enunciado fundamental supõe a existência de um atrator, ou ponto crítico, para o qual os sistemas tenderiam. Na sua proximidade, ocorreriam mudanças qualitativas súbitas, catástrofes que reorganizariam o sistema na sua globalidade, devolvendo-o a algum ponto da escala evolutiva aquém do ponto crítico (Bak, 1996). Com isso, o esquema evolutivo básico se repetiria, constituindo uma dinâmica caracterizada por sucessão de avalanches de diferentes tamanhos e de diferentes durações que, não obstante, guardariam uma relação entre si; essa relação seria expressa na forma de uma lei de potência ${ }^{3}$. Padrão evolutivo de criticalidade seria, de fato, descrito por: a) existência de um atrator ou ponto crítico identificável; e b) existência de leis de potência relacionando as ocorrências de catástrofe segundo portes e durações.

\footnotetext{
${ }^{3}$ Leis de potência descrevem distribuições de eventos por porte ou duração, quando séries históricas se mostram incapazes de identificar qualquer padrão dos tipos mais usuais, como porte crescente, intervalos regulares etc.
} 
Diferentes aplicações desse enunciado para estudos urbanos têm sido testadas, algumas específicas para detecção de padrão evolutivo da forma urbana, das quais duas serão aqui comentadas e uma terceira será apresentada em maior detalhe.

\section{Relação Crítica entre Forma Construída e Centralidade}

Elabora-se aqui a hipótese de que a ocupação de cada parcela de terra urbana seja compatível com sua hierarquia, ou seja, parcelas mais centrais teriam ocupação mais intensa, e parcelas menos centrais, mais difusa. Supondo ainda que as cidades se expandam, e, com isso, parcelas inicialmente periféricas tornem-se mais centrais, sua ocupação tenderia crescentemente a ser discrepante com sua posição relativa no sistema urbano. Em situações de crescimento urbano continuado, essa divergência entre ocupação real e ocupação "certa", quer dizer, compatível com sua centralidade, evoluiria para níveis críticos, culminando eventualmente com a substituição da edificação original por outra, que restabeleceria a apropriada relação ocupação/posição 4 . Ocorrências desse tipo poderiam surgir isolada (uma edificação eventualmente substituída) ou concentradamente (áreas urbanas sendo rapidamente reconstruídas), sempre que determinada relação entre coeficiente de aproveitamento de lotes e centralidade de áreas fosse alcançada, caracterizando, então, avalanches de diferentes tamanhos e durações, em torno de um ponto crítico.

0 padrão morfológico característico desse processo evolutivo (Figura 6) assemelha-se a um pipocar de novas edificações no interior do tecido urbano, incluindo ocorrências isoladas ou agrupadas, em diferentes escalas, a um ritmo aparentemente aleatório, entretanto dispostos - tanto quantidades quanto tempos, segundo uma distribuição descrita por uma lei de potência (Krafta et al., 2011), bem como referenciadas a ponto crítico identificável.

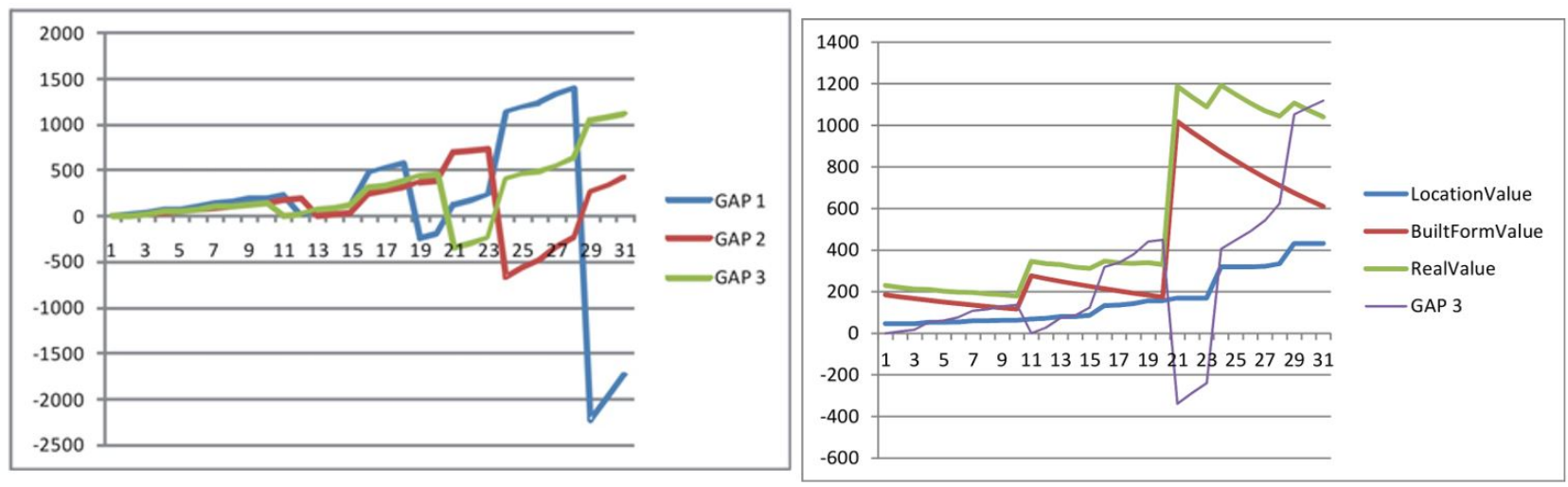

Figura 6 - Simulação da evolução e substituição de formas construídas (esquerda) conforme evolução da centralidade dos respectivos lotes (direita), mostrando ponto crítico observável e catástrofes sequenciais. Fonte: Krafta et al., Urban Built Form Grows Critical, Cybergeo 565.

\section{Distância Máxima Média Crítica}

De forma análoga, assume-se que áreas residenciais e comerciais urbanas sejam, respectivamente, vetores de dispersão e de concentração da forma da cidade. Supondo que se desenvolvam de maneira relacionada, a cidade se expandiria por meio de novas áreas residenciais, mantendo seu centro funcional, até um ponto crítico a partir do qual esse centro sofreria mudanças qualitativas, extravasando seus limites ou propiciando a emergência de centros secundários. Essa seria uma relação crítica, determinada pela distância máxima entre o mais periférico ponto de oferta de serviço e o extremo residencial do tecido

\footnotetext{
${ }^{4}$ Para mais informação sobre esse processo, ver Smith (1987).
} 
urbano. Claro que ocupação residencial ocorre tanto por expansão como por densificação, então a relação de distância entre localizações residenciais e de serviço deveria ser expressa como uma média de todas as distâncias desde cada localização residencial e cada localização comercial. Pelo enunciado geral da criticalidade auto-organizada, uma vez atingida a distância crítica, modificações qualitativas no sistema de serviços deveriam ocorrer na forma de emergência de novas unidades fora do limite da área central, em locais que efetivamente diminuíssem a distância máxima média e restabelecessem a relação estrutural. Essas ocorrências incluiriam desde unidades de serviço isoladas até novos centros comerciais, com diferentes escalas entre esses extremos, todos inter-relacionados por uma lei de potência. Semelhantemente ao caso anterior, o padrão evolutivo aqui seria caracterizado pelo "vazamento" do centro em direção à periferia urbana, usualmente de forma dendrítica, ao longo das vias de acesso principais, bem como pelo aparecimento de unidades de serviços separadas do centro, segundo quantidades e tempos de ocorrência diferenciados, porém relacionados (Figura 7). Uma investigação desse tipo de dinâmica foi levada a cabo na cidade de Santa Maria/RS, produzindo evidências preliminares (Krafta \& Bevilacqua, 2016).
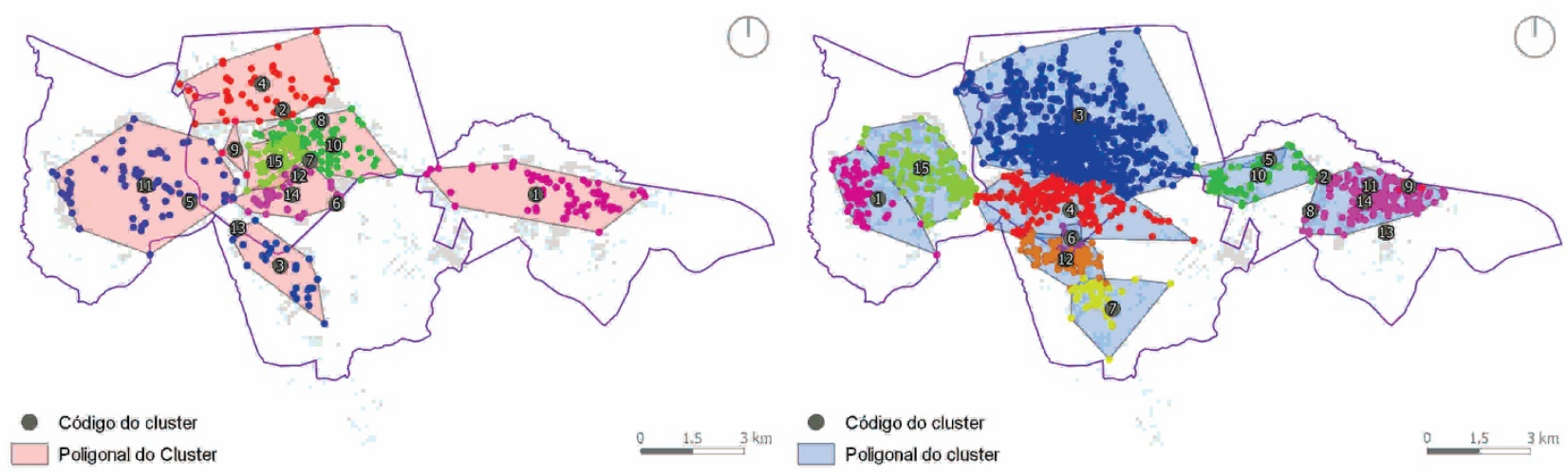

Figura 7 - Dinâmica das localizações de serviço, por análise de clusters, correspondente à evolução da área urbanizada de Santa Maria/RS. Fonte: Krafta \& Bevilacqua, 2016, Características e Medidas do Urbano, Revista Brasileira de Cartografia.

\section{Um caso de Criticalidade Auto-organizada da Forma Urbana: Expansão versus Densificação na cidade de Santa Maria/RS}

\section{Perfil}

Este estudo produz evidências de que os processos de expansão urbana (aumento da área urbanizada) e de densificação (concentração de área construída nos limites da área urbanizada) - justamente os dois processos fundamentais de transformação quantitativa e qualitativa da forma urbana - estariam relacionados. Essa relação, entretanto, não é facilmente identificável, como também não repete padrões mais comumente conhecidos da evolução urbana.

\section{Fundamentos}

Sua verificação exigiu uso de estatística derivada da teoria da criticalidade auto-organizada (Bak, 1996). Na ótica desse campo teórico da física, inúmeros processos existentes nos sistemas naturais e sociais são caracterizados por incluírem um atrator, denominado ponto crítico, para o qual os sistemas tendem; ao atingirem ou se aproximarem dele, tornam-se instáveis e propensos a sofrer mudanças súbitas - catástrofes, ou avalanches -, que os forçam a retornar a um estado de equilíbrio temporário, 
para, novamente, evoluir na direção do ponto crítico e experimentar instabilidade. Ainda nessa ótica, a verificação de um processo desse tipo envolve a identificação do ponto crítico e o exame estatístico das avalanches. Estas são imprevisíveis em termos de magnitude e duração; logo, são refratárias ao tratamento estatístico usual, dos tipos correlação ou regressão. Assim, sua ocorrência somente seria descrita por uma distribuição segundo leis de potência, isto é, frequências de magnitude e de duração distribuídas de acordo com uma escala de quantidades estruturada (maior número de ocorrências de pequena magnitude, até número reduzido de ocorrências de grande magnitude, ordenadas).

Nas cidades, expansão e densificação mostram características muito diferentes entre si: enquanto densificação se dá por acréscimos infinitesimais, dispersos no tecido urbano e muito frequentes, expansão segue caminho inverso, com acréscimos relativamente grandes, geralmente na periferia do tecido urbano e a tempos mais longos. Esses dois padrões são quase opostos; não obstante, parecem ter uma relação: a quantidade de área construída depositada no interior do tecido urbano cresce continuamente por causa do acréscimo de pequenas quantidades espalhadas pela cidade, quase todo dia, aumentando continuamente a densidade. 0 crescimento continuado da densidade é, entretanto, interrompido no momento preciso em que um novo loteamento é acrescido à área urbana. Nesse momento, a densidade sofre uma queda abrupta, retornando a um nível inferior ao que apresentava no momento imediatamente anterior à inclusão do novo loteamento; contudo, imediatamente retoma sua rotina de crescimento, até que nova catástrofe ocorra e a faça recuar uma vez mais.

Essa é uma relação dinâmica inegável existente entre densificação e expansão, e a hipótese é que seja do tipo C.A.O.; para isso, seria necessário identificar a existência de um ponto crítico, isto é, demonstrar, primeiro, que a sucessão dos pontos exatos em que ocorre queda abrupta de densidade está ordenada de alguma forma. Seria ainda preciso, em segundo lugar, demonstrar que as catástrofes - os novos loteamentos - estariam ordenadas segundo porte e frequência; certamente não um ordenamento simples do tipo porte crescente ou decrescente, ou frequência constante, mas uma distribuição segundo lei de potência.

\section{Métodos}

A verificação de um processo de criticalidade auto-organizada envolve normalmente a explicitação de dois elementos: a) existência de um ponto crítico discernível; e b) distribuição de catástrofes segundo lei de potência, com parâmetros comparáveis a outros já identificados. Para a investigação acerca do ponto crítico, decidiu-se testar três diferentes indicadores de hierarquia espacial: densidade média, densidade máxima e centralidade ponderada. 0 mais simples deles, densidade média, foi definido como uma relação direta entre área urbanizada e área construída totais. A densidade máxima, de modo análogo, foi definida como a mesma relação, dessa vez tomada de uma única unidade espacial, a mais densa. Conceito básico da centralidade ponderada (veja seção Modelo de Centralidade), betweenness em um grafo considera central todo nó encontrado no caminho mínimo entre dois outros. Assim, se o caminho mínimo entre nós "a" e "b" inclui o nó "c", este é central para o par "a-b". Verificando todos os pares do grafo, por adição se chega à centralidade geral do sistema. A ponderação considerada a esse mecanismo foi dada pela inclusão de duas novas variáveis - distância, ou extensão, dos caminhos mínimos, e massa, ou conteúdo, dos nós. Medida de distância considerada foi a extensão de cada caminho mínimo (número de nós interpostos entre cada par), enquanto massa passou a ser a área construída existente em cada nó. 0 algoritmo utilizado para calcular isso inclui os seguintes passos:

a) pesquisa de caminhos mínimos entre cada par i e j do grafo;

b) cálculo da tensão entre cada par pela equação $t_{i j}=f_{i} f_{j}$;

c) cálculo da centralidade de cada nó k presente no caminho mínimo entre i e j pela equação $t_{i j}(k)=f_{i} f_{j} / n$, em que n é o número total de nós presentes nos caminhos mínimos entre i e j, incluindo estes; 
d) cálculo da centralidade de cada nó após processamento de todos os pares do grafo pela equação $t_{k}=\sum_{\substack{i, j \\ i<j}}^{n}(k)$.

A descrição espacial adotada foi um mapa de segmentos, correspondendo à configuração atual da cidade escolhida para testes, a partir do qual foram produzidos mapas para cada ano da série temporal, por meio da retirada dos segmentos inexistentes em cada período. Com isso, foi possível gerar duas descrições do sistema: uma imediatamente anterior e outra imediatamente posterior ao aparecimento de cada novo loteamento no período considerado. Com base nessas descrições, os três indicadores foram calculados, gerando séries de medidas distribuídas segundo uma temporalidade irregular (cada par de medidas feito na data da inclusão de cada novo loteamento), testados quanto à estacionaridade e autocorrelação, e plotados segundo temporalidade normalizada.

Para verificação das catástrofes, foram produzidas séries ordenadas por porte (área de cada novo loteamento) e duração (tempo decorrido entre cada novo loteamento e o seguinte), para o período considerado. Com isso, foi procedida à verificação de existência de ordem, expressa por eventuais leis de potência.

\section{Verificação empírica}

0 mapa de segmentos de Santa Maria contém 7.552 unidades, correspondendo à configuração atual da cidade (2016). A partir dele foram produzidos, primeiro, um mapa inicial, tempo t0, no qual cada segmento foi carregado com as respectivas áreas urbanas e construídas, correspondendo ao ano de 2002 (está claro que segmentos inexistentes nesse ano foram desconsiderados), e tantas atualizações quantas inclusões de novos loteamentos ocorreram até 2016. Após processar o cálculo das diferentes medidas de hierarquia espacial e fazer testes estatísticos preliminares, estas foram comparadas, mediante análise de regressão, à linha de evolução da área construída do período, resultando em verificação de regularidade e consequente capacidade preditiva com confiabilidade de $94,55 \%$ e $97,75 \%$ para densidade média e centralidade ponderada, respectivamente. Isso significa que a centralidade ponderada do sistema, medida a cada ponto de ocorrência de uma catástrofe, constrói uma trajetória evolutiva regular, equivalente à definição de um ponto crítico. É claro que o ponto crítico não é fixo, já que a centralidade, assim como a densidade, tende a crescer, apesar de apresentar um padrão evolutivo definido.

Para verificação dos eventos, foram construídas duas séries: uma ordenada por tamanho dos loteamentos e outra pelo tempo decorrido entre cada um e o seguinte, abrangendo um período de 100 anos (1916-2016) e 279 loteamentos (Krafta \& Silva, 2019). Em ambas foram identificadas distribuições segundo leis de potência, grau de potência -1.059 para tamanhos e -0,969 para duração Figuras 8 e 9. Esses graus de potência situam-se dentro de intervalo de variação encontrados em outros estudos similares (Batty, 2007). 

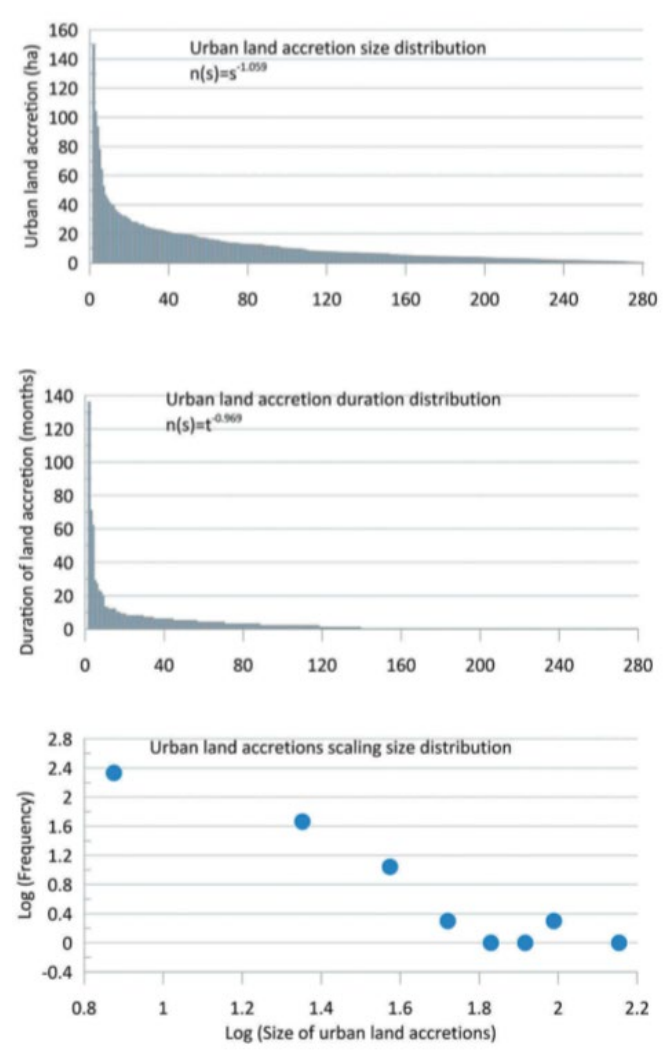

Figura 8 - Evolução dos acréscimos de área urbanizada por tamanho e duração, distribuídos segundo uma lei de potência (superiores), e distribuição dos loteamentos por tamanho (inferior). Fonte: Krafta \& Silva, 2019, Self-organized Criticality and Urban Form Systems Dynamics with reference to a Brazilian City, Area Development and Policy.
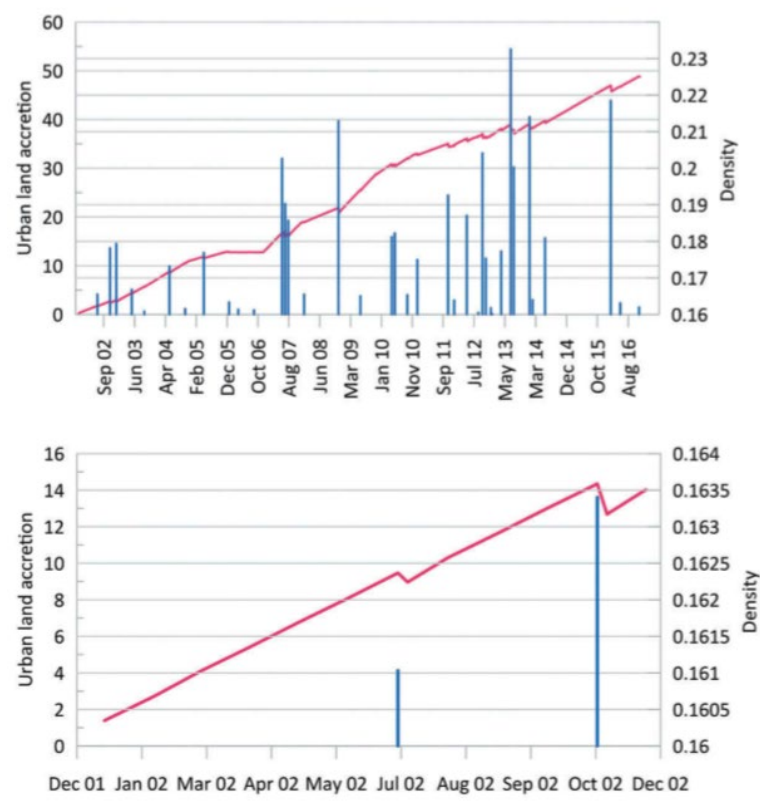

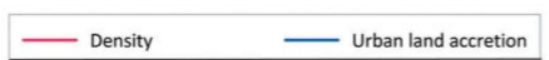

Figura 9 - Evolução da densidade média e dos acréscimos de área urbanizada (superior) e detalhe dos momentos de queda da densidade pelo aumento da área (inferior). Fonte: Krafta \& Silva, 2019, Self-organized Criticality and Urban Form Systems Dynamics with reference to a Brazilian City, Area Development and Policy. 


\section{Conclusão}

A Tabela 1, já apresentada e examinada em maior detalhe, sugere um longo caminho percorrido na busca, identificação e representação de padrões da forma urbana, mostrando várias vertentes e constantemente derivando novas. Como seria de se esperar, o estudo da forma urbana iniciou-se com descrições e análises predominantemente figurativas, estendendo-se no sentido de maior abstração, na tentativa de revelar padrões mais elusivos, particularmente aqueles associados à dinâmica de mudanças e evolução. Iniciando sua trajetória como uma hipótese de disciplina autônoma, eventualmente capaz de revelar aspectos essenciais do fenômeno urbano a partir de sua forma, parece ter alcançado hoje reconhecimento e interação com outras áreas do conhecimento urbano suficientes para caracterizá-la como imprescindível ao estudo da cidade.

Dois fatores podem ter sido essenciais para o desenvolvimento da morfologia urbana contemporânea enquanto um campo de conhecimento específico, tanto em seu desempenho recente quanto nas suas perspectivas de desenvolvimento futuro: sua associação à ciência da complexidade e à física estatística. As cidades têm sido frequentemente referidas como exemplos de auto-organização, não apenas como organismo social, mas também, espacialmente, revelando uma dinâmica claramente convergente à dos sistemas complexos: grande número de componentes, interação local e forma emergente. Batty (2007) lembra, no que se refere ao porte, que a cidade de Londres teria um número possível de diferentes configurações maior do que a quantidade de átomos do universo! Interação local é igualmente constatável tanto no âmbito dos agentes sociais (cada um interage com uma parcela ínfima de outros) quanto espaciais (cada lugar ou unidade espacial qualquer possui um número muito limitado de vizinhos). Não obstante, considerando a simultaneidade das relações de cada um com seus parceiros de interação, o resultado macro é emergente, quer dizer, imprevisível. Significa que a dinâmica desenvolvida por sistemas assim constituídos é instável, incerta, sujeita a mudanças de estado bruscas, com propagação multiplicativa de efeitos; em resumo, evolui segundo padrões não lineares. A captura desses padrões acaba sendo possível apenas por meio de estatística espacial. 0 caso aqui apresentado ilustra isso ao examinar um sistema composto de milhares de edificações, centenas de loteamentos, agenciados por uma enorme quantidade de agentes, distribuídos sobre um território urbano ao longo de muitos anos que acabam mostrando ter relações bastante precisas entre si. Tais relações não são visíveis, por assim dizer, visto que a distribuição de novas edificações é dispersa e microscópica, a sucessão de loteamentos não obedece padrão de tamanho, posição ou temporalidade, os agentes promotores são autônomos e desconhecem, em larga medida, as ações uns dos outros; tudo isso sugere aleatoriedade, até que um outro tipo de verificação estatística revela um padrão e sugere a existência de uma dinâmica de sucessivas catástrofes rondando um atrator.

As cidades têm sido insistentemente descritas como um fenômeno de interação de forças econômicas e espaciais centrípetas e centrífugas contrapostas e simultâneas, quando a resultante tanto pode ser de centralização quanto de difusão, conforme as circunstâncias evolucionárias (Fujita \& Mori, 1997; Thisse, 2014; Fujita \& Thisse, 2009). 0 estudo aqui apresentado, embora realizado a partir de uma abordagem exclusivamente morfológica, mostra uma dinâmica muito similar, com períodos de centralização (aumento de densidade) e eventos de dispersão (ocorrência de novos loteamentos), segundo uma distribuição reconhecível e até previsível. Não há evidência de que essa evolução corresponda em alguma medida à dinâmica descrita pela economia espacial, mas é muito instigante vê-la graciosamente convergir, sugerindo que, afinal, a representação das cidades por meio de variáveis morfológicas pode produzir resultados equivalentes, em poder explanatório, aos revelados por outras áreas da ciência voltadas ao seu estudo.

\section{Referências}

Aymonino, C. (1975). Il significato delle città. Veneza: Laterza.

Bak, P. (1996). How nature works: The science of self-organized criticality. Berlin: Springer.

http://dx.doi.org/10.1007/978-1-4757-5426-1.

Ball, Ph. (2004). Critical Mass: How one thing leads to Another. New York: Farrar, Straus \& Giroux. 
Barthelemy, M. (2019). The statistics physics of cities. Nature Review Physics, 1(6), 406-415.

Batty, M. (2007). Cities and Complexity: Understanding cities with cellular automata, agent-based models and fractals. Cambridge: MIT Press.

Batty, M., \& Longley, P. (1994). Fractal Cities. San Diego: Elsevier.

Bettencourt, L., \& West, G. (2010). A unified theory of urban living. Nature, 467(7318), 912-913. http://dx.doi.org/10.1038/467912a. PMid:20962823.

Cataldi, G., Maffei, G. L., \& Vaccaro P. (2002). Saverio Muratori and the Italian School of Planning Typology. Urban Morphology, 6, 3-20.

Constantinou, E., \& Krafta, R. (2007). Built Form Change: Randomness and Emergence of Space-time Patterns. Ouro Preto. In Proceedings of the International Seminar on Urban Form (pp. 1-17). Ouro Preto: UFMG.

Conzen, M. R. G. (1988). Morphogenesis, morphological regions and secular human agency. in The Historic Townscape, as exemplified by Ludlow. In D. Denecke, \& G. Shaw (Eds.), Urban historical geography: Recent Progress in Britain and Germany (pp. 252-272.). Cambridge: Cambridge University Press.

Freeman, L. (1977). A Set of Measures of Centrality based on Betweenness. Sociometry, 40(1), 35-41. http://dx.doi.org/10.2307/3033543.

Fujita, M., \& Mori, T. (1997). Structural stability and evolution of urban systems. Regional Science and Urban Economics, 27(4-5), 399-442. http://dx.doi.org/10.1016/S0166-0462(97)80004-X.

Fujita, M., \& Thisse, J. F. (2009). New Economic Geography: An appraisal on the occasion on Paul Krugman's 2008 Nobel Prize in Economic Science. Regional Science and Urban Economics, 39(2), 109-119.

http://dx.doi.org/10.1016/j.regsciurbeco.2008.11.003.

Gauthier, B. (2004). The history of urban morphology. Urban Morphology, 8, 71-90.

Hansen, G. (1959). How accessibility shapes land use. Journal of the American Institute of Planners, 25(2), 73-76. http://dx.doi.org/10.1080/01944365908978307.

Hillier, B., \& Hanson, J. (1985). The social logic of space. Cambridge: University Press.

Ingram, D. R. (1971). The Concept of Accessibility: a search for an operational form. Regional Studies, 5(2), 101105. http://dx.doi.org/10.1080/09595237100185131.

Krafta, R. (1994). Modelling Intra-Urban Configurational Development. Environment \& Planning B, 21(1), 67-82. http://dx.doi.org/10.1068/b210067.

Krafta, R. (1997). Urban Convergence: morphology and Attraction. Environment \& Planning B, 23(1), 37-48. http://dx.doi.org/10.1068/b230037.

Krafta, R. (2014). Notas de Aula de Morfologia Urbana. Porto Alegre: Editora da UFRGS.

Krafta, R., \& Bevilacqua, D. (2016). Características e Medidas do Urbano: Relações Espaciais Críticas entre Serviços Urbanos e Usuários. Revista Brasileira de Cartografia, 68(4), 843-861.

Krafta, R., Netto, V., Lima, L. (2011). Urban Built Form Grows Critical. Cybergeo, 565, 11-26.

Krafta, R., \& Silva, E. B. (2019). Self-organized Criticality and Urban Form System Dynamics with reference to a Brazilian city. Area Development and Policy. 4, 1-10. http://dx.doi.org/10.1080/23792949.2019.1631124.

Maraschin, C., Krafta, R. (2013). Growth dynamics of retail location: A methodological approach using a logistic model. Cybergeo, 650.

March, L. (2010). The Architecture of Form. Cambridge: University Press.

March, L., \& Steadman, P. H. (1971). The geometry of environment. Londres: RIBA Pub.

Martin, L. (1972). The Grid as Generator. In L. Martin (Ed.), Urban Space and Structures. Cambridge: University Press. 
Picinato, L. (1947). La città come organismo. Veneza: Marsiglio.

Polidori, M., \& Krafta, R. (2005). Modelando crescimento urbano com integração de fatores urbanos, ambientais e institucionais. Geofocus, 5, 156-179.

Pont, M. B., \& Haupt, P. (2009). Space, density and urban form. Delft: TU Delft.

Porto Alegre. (1979, 21 de julho). Lei Complementar n. 43, de 21 de julho de 1979. Dispõe sobre o desenvolvimento urbano no município de Porto Alegre, institui o primeiro plano diretor de desenvolvimento urbano, e dá outras providências. Porto Alegre: Diário Oficial de Porto Alegre.

Rossi, A. (1998). A arquitetura da cidade. São Paulo: Martins Fontes.

Smith, N. (1984). Uneven Development - Nature, Capital and the Production of Space. Atlanta: The University of Georgia Press.

Smith, N. (1987). Gentrification and the rent gap. Annals of the Association of American Geographers, 77(3), 462465. http://dx.doi.org/10.1111/j.1467-8306.1987.tb00171.x.

Steadman, P. H. (2001). A binary encoding of a class of rectangular built forms. In Proceedings of 3rd International Space Syntax Symposium. Atlanta.

Thisse, J. F. (2014). The New Science of Cities by Michael Batty: The opinion of an economist. Journal of Economic Literature, 52(3), 805-819. http://dx.doi.org/10.1257/jel.52.3.805.

White, R., Engelen, G., \& Uljee, I. (1997). The use of constrained cellular automata for high-resolution modelling of urban land-use dynamics. Environment \& Planning B, 24(3), 323-343. http://dx.doi.org/10.1068/b240323.

Editores convidados: Vitor Oliveira (Universidade do Porto, Portugal) e Bruno Zaitter (PUCPR, Brasil)

Recebido: Ago. 012019

Aprovado: Abr. 102020 